\title{
PROGRAM PRESTO - PREPARATION OF REFERENCE ENERGY SYSTEMS THROUGH TIME
}

\author{
E. BEARDSWORTH AND G. GOLDSTEIN
}
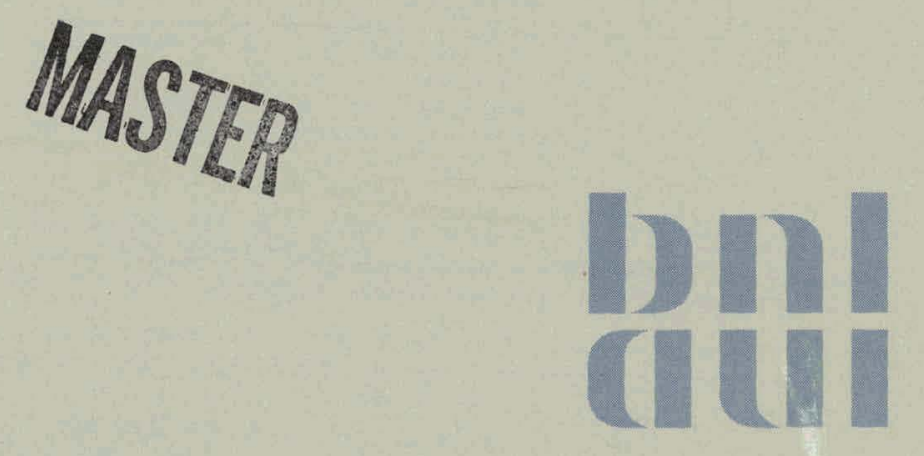

August 1977

DEPARTMENT OF NUCLEAR ENERGY

BROOKHAVEN NATIONAL LABORATORY

ASSOCIATED UNIVERSITIES, INC.

UNDER CONTRACT NO. EY-76-C-02-0016 WITH THE

UNITED STATES DEPARTMENT OF ENERGY 


\section{DISCLAIMER}

This report was prepared as an account of work sponsored by an agency of the United States Government. Neither the United States Government nor any agency Thereof, nor any of their employees, makes any warranty, express or implied, or assumes any legal liability or responsibility for the accuracy, completeness, or usefulness of any information, apparatus, product, or process disclosed, or represents that its use would not infringe privately owned rights. Reference herein to any specific commercial product, process, or service by trade name, trademark, manufacturer, or otherwise does not necessarily constitute or imply its endorsement, recommendation, or favoring by the United States Government or any agency thereof. The views and opinions of authors expressed herein do not necessarily state or reflect those of the United States Government or any agency thereof. 


\section{DISCLAIMER}

Portions of this document may be illegible in electronic image products. Images are produced from the best available original document. 
BNL 50723

UC-20

(Magnetic Fusion Energy - TID-4500)

\title{
A \\ PROGRAM PRESTO - PREPARATION OF REFERENCE ENERGY SYSTEMS THROUGH TIME
}

\author{
E. Beardsworth AND G. GOLDSTEIN
}

August 1977

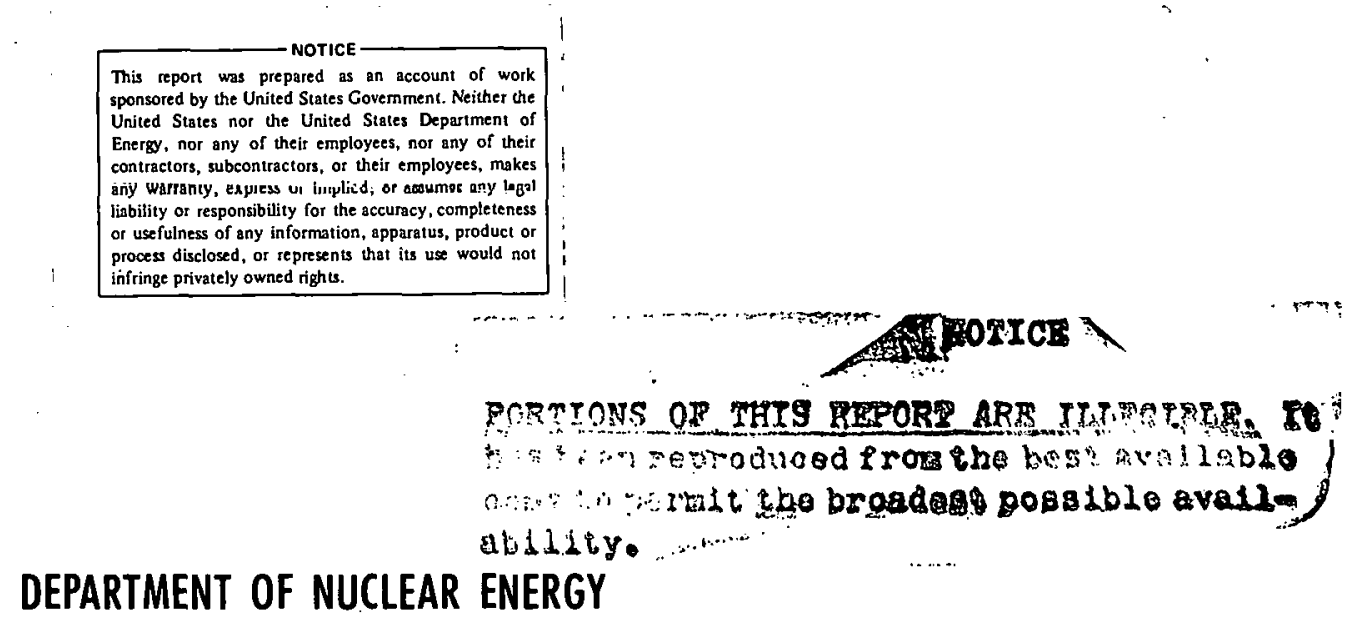

BROOKHAVEN NATIONAL LABORATORY UPTON, NEW. YORK 11973 
NOTICE

This report was prepared as an account of work sponsored by the United Statcs Government. Neither the United States nor the United States Department of F.nergy (UUE), nor any of their employees, nor any of their contractors, subcontractors, or

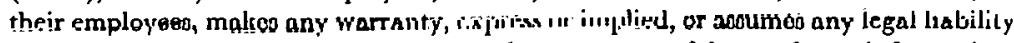
or responsibility for the accuracy, completeness or usefulness of any information, apparatus, product or process disclosed, or represents that its use would not infringe privately owned rights.

Printed in the United States of America Available from

National Technical Information Service

U.S. Department of Commerce

5285 Port Royal Road

Springfield, VA 22161

Price: Printed Copy $\$ 4.00$; Microfiche $\$ 3.00$

Decembcr 1977

250 copies 


\begin{abstract}
$\underline{\text { ABSTRACT }}$
PRESTO is an interactive computer program to provide a convenient framework for energy accounts to specify quantitatively the flows in the U.S. energy system over time, and to permit manipulation of their values while maintaining internal consistency. Then, once a scenario is defined, several of its attributes and implications are calculated (costs, total resource use, and environmental effects.) It is based on the Reference Energy System methodology, a diagrammatic description of energy flows, but with the explicit incorporation of the time dimension.
\end{abstract}




\section{TABLE OF CONTENTS}

$\underline{\text { Page }}$

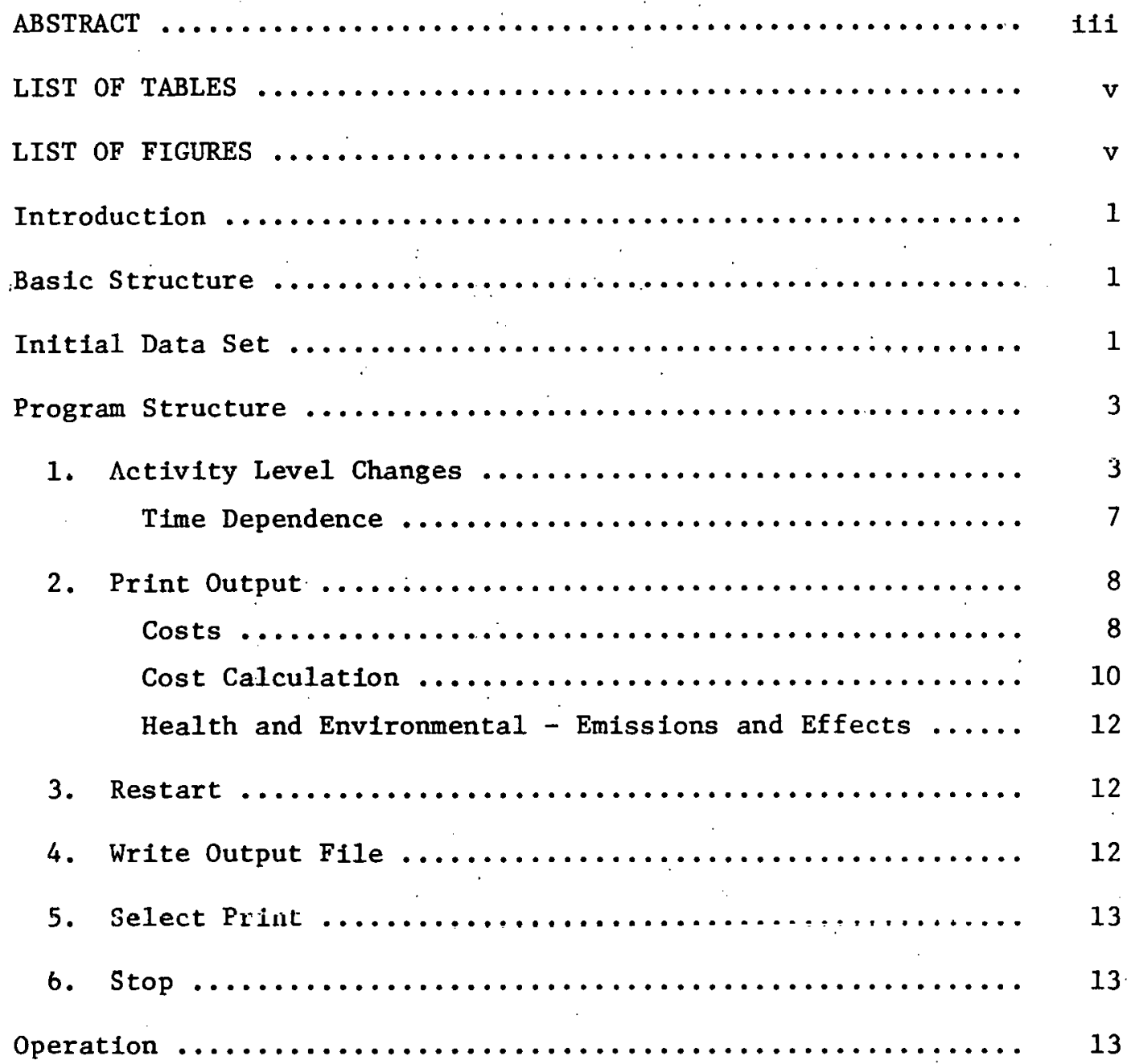


TABLE 1

TABLE 2

TABLE 3

TABLE 4

TABLE 5

\section{LIST OF" FIGURES}

FIGURE 1

PRESTO - FLOW CHART 
Introduction

PRESTO is an interactive computer program written for use on the INTERCOM system of the Brookhaven National Laboratory Central Scientific Computing Facility. It is based on the Reference Energy System methodology, a diagrammatic description of energy flows in the U.S. energy system, with the addition of explicit incorporation of the time dimension.

The purpose of PRESTO is to provide a convenient energy accounting framework in which to specify quantitatively the flows in the U.S. energy system over time (the next 100 years), in such a way that each energy activity variable varies smoothly and reasonably over time, while bearing a consistent relationship to the other energy flows at each point in time. Then, once a given scenario is defined, several of its attributes and implications are readily.calculated and output in a convenient format.

\section{Basic Structure}

Figure 1 shows the simplified reference energy, system, with "activity" indexes indicated. Each energy activity has been assigned an index number (i.e., $\because \because \cdots, \quad \therefore$

total distributed electricity is activity 32 , total coal mined is $\$ 29$, electricity generated by coal steam is $\|_{11}$ ).

\section{Initial Data Set}

A complete, consistent set of data must be specified to initialize PRESTO. This consists of values for each of the up to ten reference years, which also must be provided as input. This initial data set must already exhibit selfconsistency in each reference year. For example:

$$
x_{20}=x_{6}+x_{34}
$$

and

$$
x_{31}=x_{7}+x_{8}+x_{9}+x_{10}+x_{11}+x_{12}
$$




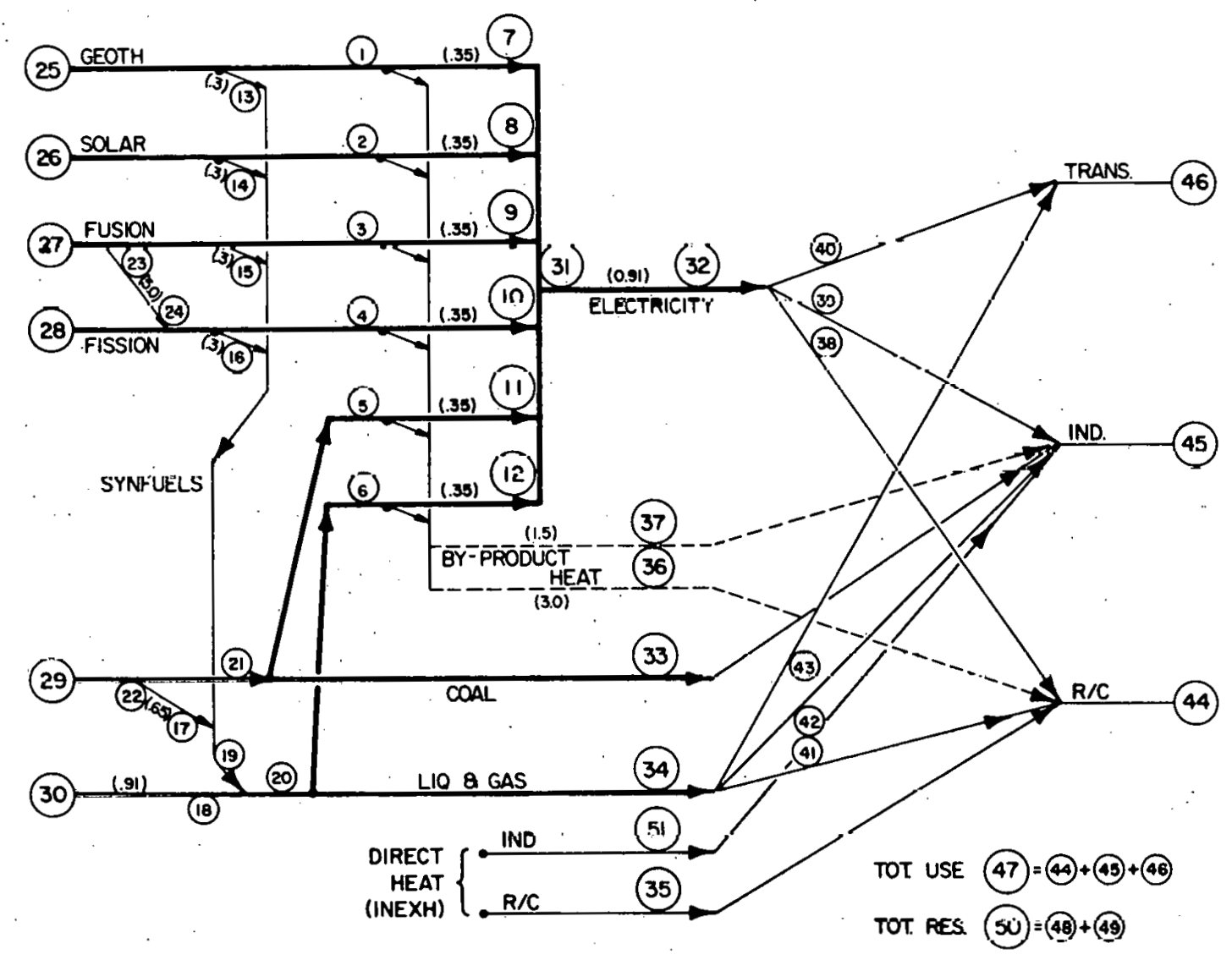

Figure 1. Presto - Flow Chart. 
Table 1 shows a sample base case specification. The first record contains a title. The second record has the list of reference years, and the rest have the values for each of the sixty variables. Once this initial data set is established, a series of interactive commands enable the user to make changes in the energy totals: At all times, a value will be specified for each activity variable, in each of the reference years.

\section{Program Structure}

Upon starting, PRESTO reads the case title, the list of reference years, and the input data file. Then costs are read in, a command list is printed, and a COMMAND WAIT state is entered. (See Figure 2.) The seven basic commands include activity level changes and printing, output, and control functions.

\section{Activity Level Changes}

Activity level changes are specified in the format:

IACT1, 1YR, AMT, IACTI

where - IYR must be one of the ten reference years

- AMT is a floating point number specifying a change to be made (in Quads)

- IACT1

- IACT2 $\{$ are activity variable indexes

Table 2 shows the complete list of activity level change commands. The "MODE" can be set as either one in which old values replace new values (MODE = 0 ". New Value") or where they are added and subtracted from existing values (MODE $=1$ "Delta").

In the "Delta" mode, when on1y IACT1 is entered (enter IACT2 =0) the amount is added to variable \#IACT1 for the year IYR. If a value for IACT2 is entered 
TABLE 1

BASE CASE SPECIFICATION

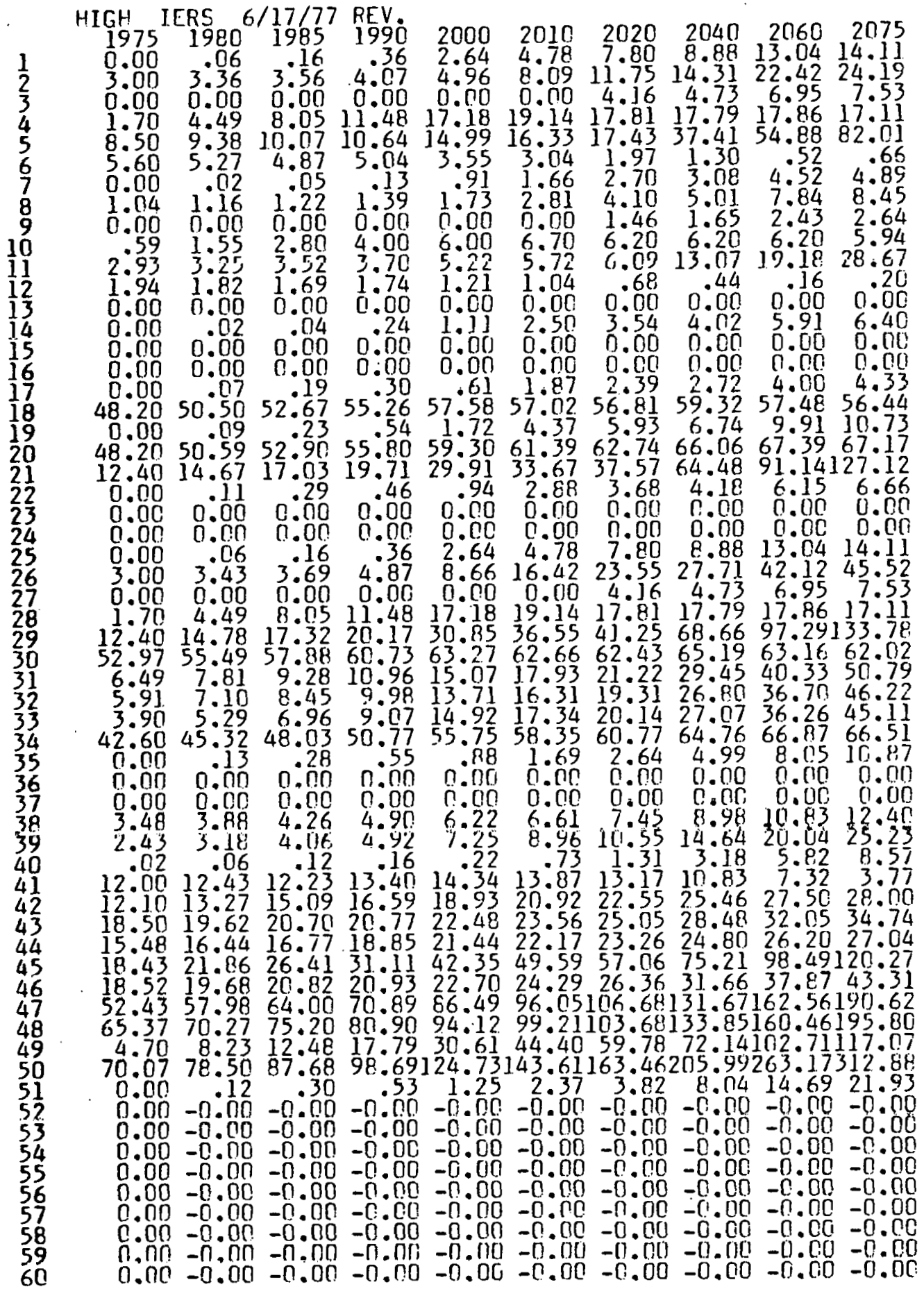


START

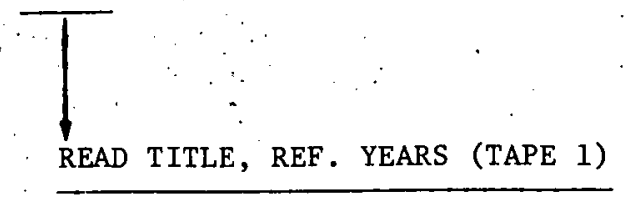

READ DATA (TAPE 1)

READ COSTS (TAPE 2 )

PRINT COMMAND LIST

COMMAND WAIT

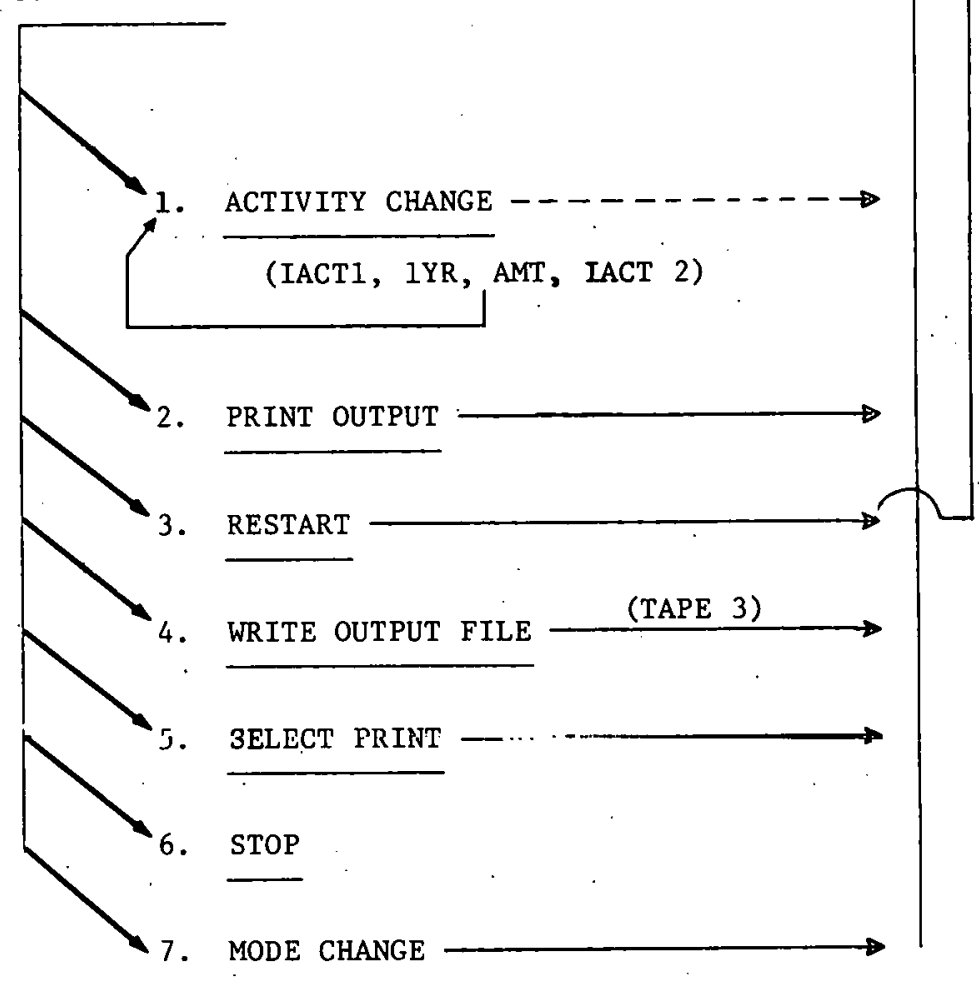

Figure 2. Program Flow Chart. 


\section{TABLE 2}

PRESTO

ACTIVITY LEVEL CHANGE COMMANDS

IACT1 IACT2

0 Scale: multiply all variables in year IYR by AMT.

$7-\left.12\right|_{38-40} ^{7-12(\neq)}$

Electric generation MIX change.

Electric generation TOTAL change, with downstream category pro-rated*.

Electric generation TOTAL change, with downstream specified.

\begin{tabular}{|c|c|c|}
\hline $13-18$ & $13-18(\neq)$ & Liq \& Gas (synfuel) supply MIX change \\
\hline 33 & 0 & Coal to Industry \\
\hline 34 & $\left\{\begin{array}{c}41-43 \\
0\end{array}\right.$ & $\begin{array}{l}\text { Iiq \& fas (direct) shango, with downctream opecificd } \\
\text { Liq \& Gas (direct) change, with downstream pro-rated* }\end{array}$ \\
\hline $\begin{array}{l}38-40 \\
41-43 \\
36,37 \\
24 \\
35 \\
51\end{array}$ & $\begin{array}{l}28-40(\neq) \\
41-43(\neq) \\
1-6 \\
28 \\
0 \\
0\end{array}$ & $\begin{array}{l}\text { Electric demand reallocation } \\
\text { Liq \& Gas demand reallocation } \\
\text { By product heat } \\
\text { Fission-fusion } \\
\text { R/C Direct Heat (solar, geoth., etc) } \\
\text { Industrial Direct Heal (solar, geull., elc) }\end{array}$ \\
\hline
\end{tabular}

* Downstream changes in fuels or electricity arc distributed among the three demand sectors in proportion to the already existing allocation. 


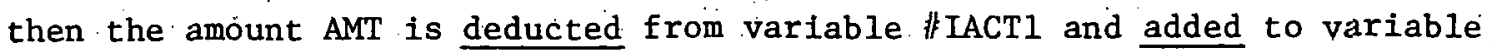
\#IACT2. In other words; that amount is transferred from IACT1 to IACT2.

In the "New.Value" mode; AMT replaces the value of variable \#IACT1, with the appropriate change to variable \#IACT2.

When any change is made that affects adjoining variables, corrected values are computed for those variables so that consistency of the flow network is maintained in that reference year. For example, a change in one of the electrical generation modes (IACT1 $=7-12$ ) with IACT2 $=0$ will result in a change in the total electric generation--so variables $\$ 31,32$, and 38,39 , and 40 are re-computed. (The final demand changes are allocated in proportion to the already existing proportions, or one demand category can be specified). If coal steam is changed, not only will the downstream (demand) variables be corrected, but so will the upstream (supply) variables: $\$ 5,21$, and 29 .

A decision structure for these corrections. is incorporated into the program to permit rapid interactive changes to be made while the program automatically maintains the consistency requirement. Extensive error checking prevents most mistaken instructions from being carried out.

\section{Time Dependence}

As changes are made to activity levels in the various reference years, the user must aim towards developing reasonable time-series in each variable. If one activity in one year is altered; the adjoining years' values will likely also require adjustments to maintain smooth variation in time. Experience is helpful in anticipating the disruptions to associated variables when some change is made. That is, a change in one variable may disrupt the time-series of some other variable. When one resource is to be gradually phased out, another 
must be brought in to replace it if the total resource consumption is to be maintained constant. This procedure can be less than straightforward, however, because of the interdependencies' which the program's decision structure are keeping consistent. The user will have to tune the quantities until all variables have satisfactory time-series.

There is one additional command which scales every activity variable in a given reference year: if IACT1 $=0$, then all activities in the reference year IYR are multiplied by AMT. This command is useful as the first step in making large changes in the total resource consumption.

\section{Print Output}

A separate subroutine requests the user to specify a "print directive pair", which indicates which of twelve subsections of the total output are to be printed, as shown in Table 3 .

Sections $1-8$ of the printout contain the activity variables. In Section 9, total cumulative resource use and an approximate attribution of primary resources to end-use categories are calculated. Certain ratios are given in section 10, e.g., the ratio of electricity to total fuels consumed. (This indicates the degree of electrification implied in the scenario.)

Costs are printed in Section 11 and environmental effects in Section 12. Each energy activity in each year is multiplied by appropriate coefficients, to tally total annual system cost, and health and environmental emissions and effects for that scenario. Costs

Up to five distinct "sets" of costs can be used simultaneously. Each successive cost set is the same as the previous one, with any number of changes 


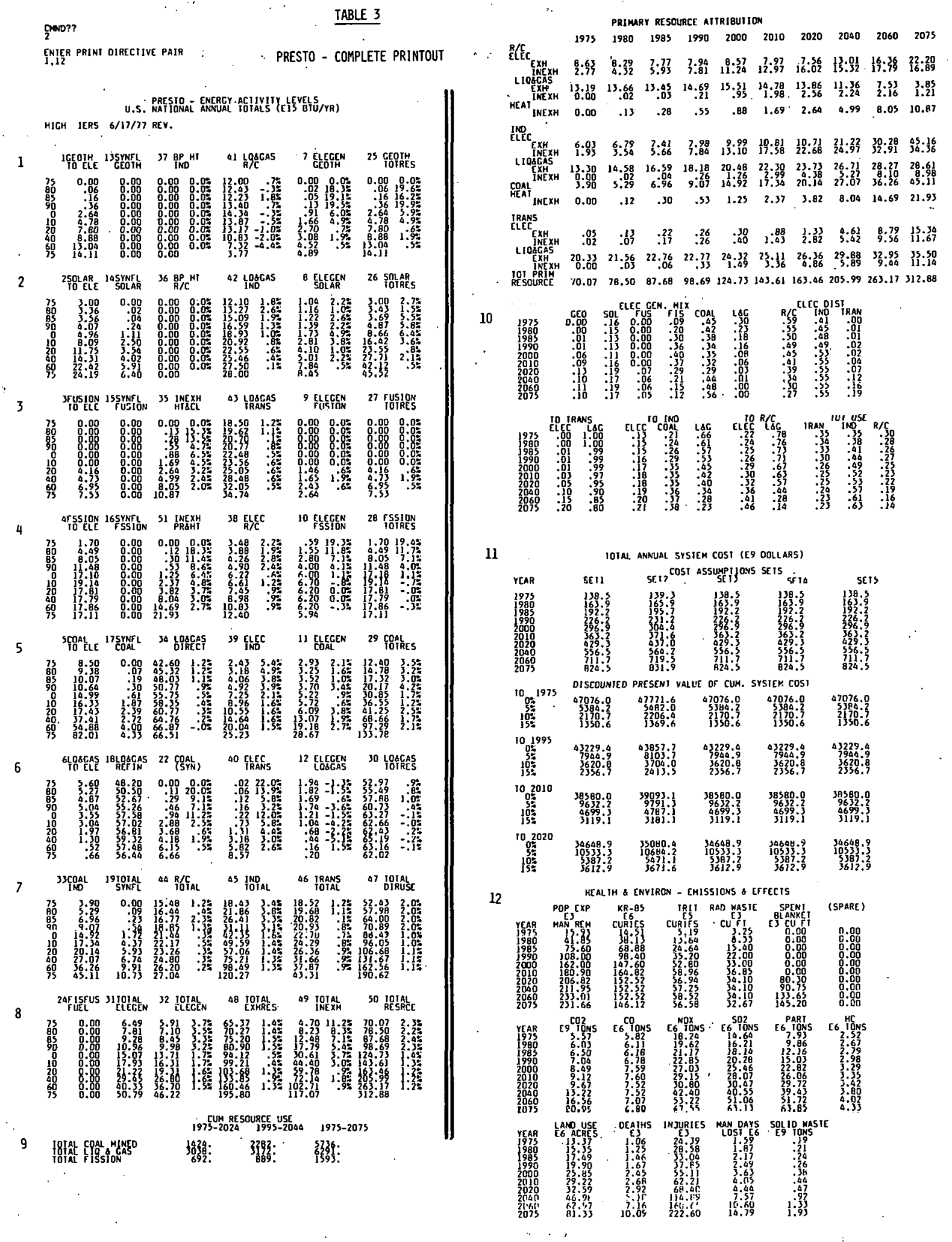


specified. In the case shown. in Table 4, cost set \#2 is the same as \#1, but with the fission capital cost (cost coefficient $\$$ 作) increased from $\$ 600$ to $\$ 800$. Cost coefficients can vary with time. If more than one point is specified (\$, year \#) then straight line interpolations are done to get the costs in the intervening reference years.

\section{Cost Calculation}

In each of the ten reference years, the annual energy system cost is computed by multiplying each of the energy activity variables by an appropriate cost coefficient and adding. This is done separately for each cost set. Capital costs (coefficient $\# 1-6,13$, and 19) are first annualized, assuming a 30-year plant life (capital recovery factor $C R F=15 \%$ and a plant factor $P F$ of 0.8 ).

$$
\text { Annualized Capital Cost }\left(\frac{\$}{1.0_{\mathrm{BTU}}}\right)=\text { Capital Cost }\left(\frac{\$}{\mathrm{~kW}}\right) \times \frac{\mathrm{CRF}}{29.9 \times \mathrm{PF}}
$$

Cummulative discounted present value of these annual cost streams* are also calculated:

$$
\operatorname{DPV}(R, Y o)=\sum_{y=Y_{0}}^{0276} \mathrm{C}(y) \frac{1}{(1+R)^{y-Y o}}
$$

where $c(y)$ is the annual system cost in the year $y$, Yo is the starting year for the calculation, and $R$ is the discount rate. Four different start years (1975, 1995, 2010, and 2020) and four different discount rates $(0,5,10$, and $15 \%)$ are applied for each cost set (See Figure C-5). Outputs for costs are in billions of dollars. Note that $\$ 1 / 10^{6}$ BTU $=\$ 10^{9} / 10^{15}$ BTU, therefore:

$$
C(y)=\underset{\text { System Cost }}{\text { Total Annual }}\left(\frac{\$ 10^{9}}{\text { year }}\right)=\sum_{i} \text { Energy }_{i}\left(\frac{10^{15} \text { BTU }}{\text { year }}\right) \times \operatorname{Cost}_{i}\left(\frac{\$}{10^{6} \text { BTU }}\right)
$$

* The total annual system cost is interpolated for all years, using a cubic spline routine. 


\section{COST DATA FILE}

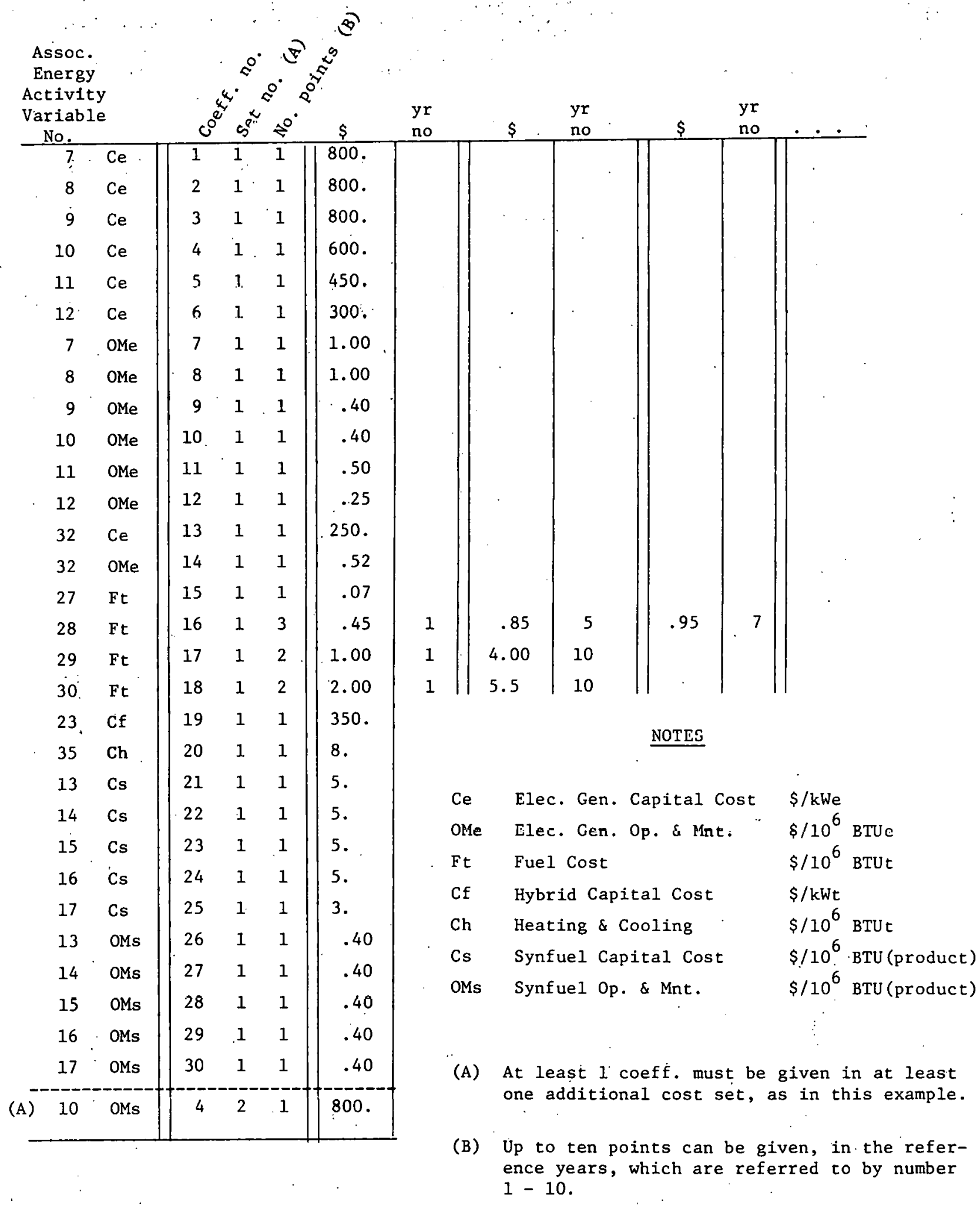


Health and Environmental - Emissions and Effects

The Energy Modeling Data Base (EMDB) provides highly specific coefficients as the individual process level for various emissions and effects resulting from energy converston and use activities.* These coefficients are in the form of amount of pollutant, or number of injuries, per BTU of energy flow. Coefficients were taken from the Data Base with an attempt to select the most representative or reasonable estimates for the more aggregated energy flow activities in PRESTO. Resulting totals should give an approximate feeling for the relative burdens to the environment imposed in the different scenarios. It should be noted, however, that it is not possible to establish truly meaningful coefficients at that level of aggregation because the individual technologies vary greatly in their characteristic emissions. (Base case fuel-allocations in more detailed studies** were used to arrive at pro-rated coefficients for the highly aggregated PRESTO energy activity variables.)

\section{Restart}

If the data become hopelessly entangled and confused, the user can restart with the original input data file. Tapes 1 and 2 are rewound and the program branches to the beginning.

\section{Write Output File}

When a case has been suitably modified, it can be saved on an output file TAPE 3 in the same format as the input file (for future use). Before writing the file, the program requests that a new title line be input. TAPE 3 is overwritten each time this comnand is executed. It is therefore necessary to exit PRESTO, and catalog the output file in order to preserve a case.

* Energy Modeling Data Base, User's Manual, Energy Environmental Group, M. Goldberg, BNL Report No. 19200.

** Sourcebook, BNL Report No. 50483. 


\section{Select Print}

During modifications, it is sometimes desirable to see portions of the data. The select print option allows any number of energy activity variable index numbers to be opecified for quick printout. PRESTO asks how many variables are to be printed and what their indexes are.

example: $4,37,38,42,50$

A special option exists to get a compact printout of ali variables:

$$
1,-1
$$

\section{Stop}

This command terminates the program after rewinding TAPE 1 and TAPE 2 .

\section{Mode Change}

The MODE is initially set in the "delta" mode, but use of this command allows it to be changed at any time.

Operation

Basic familiarity with INTERCOM is assumed.

ATTACH, TAPE 1, DATA, ID $=\mathrm{XXX}$

- A data file like the one shown in Table 5 must be ATTACHed as TAPE 1 ATTACH, TAPE 2 , COSTS, In $=\mathrm{XXX}$

- A costs file (Table 4) must be ATTACHed as TAPE 2. REQUEST, TAPE 3, *PF

- A permanent file TAPE 3 should be REQUESTed. ATTACH, PRESTO, ID $=\mathrm{XXX}$

- The program file PRESTO is ATTACHed and executed.

- After stopping PRESTO, output file TAPE 3 can be CATALOGed for future use as an input data file. 
TABLE 5

IEALTH \& ENIIRONMENTAL EMISSIONS AND EFFECTS COEFFICIENTS

$\stackrel{1}{\leftarrow}$

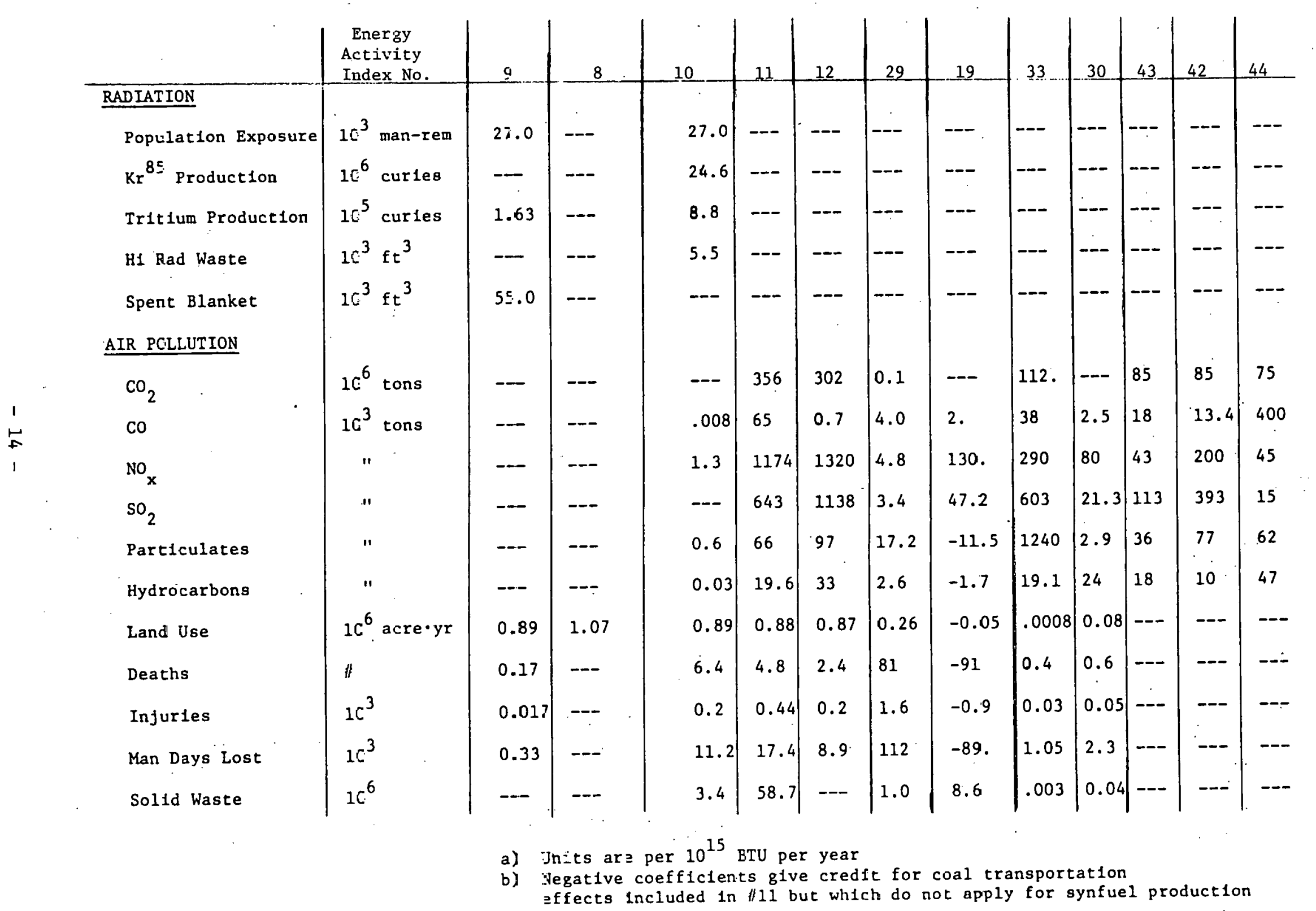

